\title{
Chlorophyll modulation of mixed layer thermodynamics in a mixed-layer isopycnal General Circulation Model-An example from Arabian Sea and equatorial Pacific
}

\author{
S Nakamoto ${ }^{1}$, S Prasanna Kumar ${ }^{2}$, J M Oberhuber ${ }^{3}, \mathrm{H} \mathrm{Saito}^{4}$, K Muneyama K $^{5}$ and \\ R FROUIN ${ }^{6}$ \\ ${ }^{1}$ Earth Science and Technology Organization, Bussan bldg Annex, 1-2-1 Nshi-shinbashi, Minatoku, Tokyo 105 \\ Japan. \\ ${ }^{2}$ Physical Oceanography Division, National Institute of Oceanography, Dona Paula, Goa 403 004, India. \\ ${ }^{3}$ DKRZ, Bundesstrasse 55, D-20146 Hamburg, Germany. \\ ${ }^{4}$ Japan Marine Science \&6 Technology Center, 2-15 Natsushima, Yokosuka 237-0004 Japan. \\ ${ }^{5}$ Marine Works Japan, 2-15 Natsushima, Yokosuka 237-0004 Japan. \\ ${ }^{6}$ Scripps Institution of Oceanography, UCSD, La Jolla, CA, 92093-0221, USA.
}

\begin{abstract}
Western tropical Indian Ocean, Arabian Sea, and the equatorial Pacific are known as regions of intense bio-chemical-physical interactions: the Arabian Sea has the largest phytoplankton bloom with seasonal signal, while the equatorial Pacific bloom is perennial with quasi-permanent upwelling. Here, we studied three dimensional ocean thermodynamics comparing recent ocean observation with ocean general circulation model (OPYC) experiment combined with remotely sensed chlorophyll pigment concentrations from the Coastal Zone Color Scanner (CZCS). Using solar radiation parameterization representing observations that a higher abundance of chlorophyll increases absorption of solar irradiance and heating rate in the upper ocean, we showed that the mixed layer thickness decreases more than they would be under clear water conditions. These changes in the model mixed layer were consistent with Joint Global Ocean Flux Study (JGOFS) observations during the 1994-1995 Arabian Sea experiment and epi-fluorescence microscopy (EFM) on samples collected during Equatorial Pacific Ocean Climate Study (EPOCS) in November, 1988. In the Arabian Sea, as the chlorophyll concentrations peak in October $\left(3 \mathrm{mg} / \mathrm{m}^{3}\right)$ after the summer plankton bloom induced by coastal upwelling, the chlorophyll induced biological heating enhanced the sea surface temperature (SST) by as much as $0.6^{\circ} \mathrm{C}$ and sub-layer temperature decreases and sub-layer thickness increases. In the equatorial Pacific, modest concentrations of chlorophyll less than $0.3 \mathrm{mg} / \mathrm{m}^{3}$ is enough to introduce a meridional differential heating, which results in reducing the equatorial mixed layer thickness to more than $20 \mathrm{~m}$. The anomalous meridional tilting of the mixed layer bottom enhances off equatorial westward geostrophic currents. Consequently, the equatorial undercurrent transports more water from west to east. We proposed that these numerical model experiments with use of satellite and in situ ocean observations are consistent under three dimensional ocean circulation theory combined with solar radiation transfer process.
\end{abstract}

\section{Introduction}

Changes in climate are related to different modes of operation of the ocean-atmosphere system as well as land-ocean system involving bio-chemical processes, which are driven by insolation fluctuation spatially and temporally on different scales. The key physical features are water transport in

Keywords. Mixed-layer; isopycnal model; phytoplankton bloom; radiation-transfer; equatorial Pacific; Arabian Sea; JGOFS; geostrophic current. 
the atmosphere and salt transport in the ocean, which together determine ocean density and circulation patterns. Changes in ocean circulation, thus, affect the exchange of trace gases including carbon dioxide between the ocean and atmosphere as well as chemical components and biological components in the ocean. The potential for feedback effects on the earth system exists through both physical and bio-chemical reactions in the oceanatmosphere-land system.

Marine phytoplanktons influence the air-sea exchanges of carbon dioxide, sulfur compounds, and ocean radiation transfer as well as albedo of ocean surface water, which affect earth climate system through thermodynamical processes within the closed system of the planet earth.

It has long been recognized that absorption of solar radiation and the resulting local heating within the upper ocean are strongly influenced by chlorophyll concentration (e.g., Ivanoff 1977; Simonot et al 1988; Lewis et al 1990; Morel and Antoine 1994). Martin (1985) compared different mixed layer models for some simple, idealized forcing cases and tested the models using mixed-layer observational data. He found that the model simulation was particularly sensitive to seawater turbidity when the penetration of solar radiation below the mixed layer is capable of influencing the temperature development at the mixed layer base. The changes in ocean turbidity affected calculated SST by $3^{\circ} \mathrm{C}$ or more, and the change due to turbidity was as large as $1^{\circ} \mathrm{C}$ on daily time scales (Martin 1985). Using numerical model experiment results, Sathyendranath et al. (1991) demonstrated a significant biological impact on the Arabian Sea's sea surface temperature (SST). Assuming that SST and vertical temperature gradient at the mixed layer base are known at the start of each month, they integrated the model over one month using monthly mean air-sea fluxes for momentum and heat to obtain new fields. Here, we investigate the role of chlorophyll pigment concentration on influencing mixed layer thermodynamics in the Arabian Sea and in the eastern equatorial Pacific using an ocean isopycnal general circulation model.

\section{Model and forcing}

Since the mixed layer depth is influenced not only by local vertical mixing but also by horizontal convergence of mass and heat, a mixed layer model must consider both full dynamics due to the use of primitive equations and a parameterization for the vertical mass transfer and related quantities across the mixed layer base. The primitive equation ocean model used in this study, hereafter referenced to as OPYC, is an updated version of the model developed by Oberhuber (1993). It is an isopycnal model with an actively coupled mixed layer and detailed flux parameterization. The model covers global ocean from North Pole to Antarctica, with sea ice processes included. The model resolution is 1 degree zonally and 1 degree meridionally with thirteen vertical layers consisting of the top mixed layer and twelve underlying isopycnal layers. A realistic topography is used from NOAA topography data, which is based on 5 minute resolution. In the OPYC model it is assumed that a fraction of the solar radiation penetrates through the ocean with exponentially decaying length of $23 \mathrm{~m}$ (Paulson and Simpson 1977), hereafter referred to as clear-water parameterization (A).

In order to study the effect of chlorophyll pigment on solar radiation penetration in surface mixed layer, the clear-water parameterization (A) is replaced by an alternative parameterization accounting for a heating rate by chlorophyll pigments within the upper ocean (Morel and Antoine 1994), hereafter referred to as chlorophyllpigment parameterization (B). This parameterization allows one to calculate the vertical profiles of heating rate from remotely-sensed chlorophyll pigment concentration data, considering partitioning between "visible" and "near IR" radiation and the vertical profile of heat deposition [Morel and Antoine 1994].

Note that the clear water parameterization implicitely includes chlorophyll pigment effects, but corresponding to only a few hundredths of $\mathrm{mg} / \mathrm{m}^{3}$. The surface forcing of the OPYC model, when used with either $(\mathrm{A})$ or $(\mathrm{B})$, consists of a climatological monthly mean seasonal cycle of wind stress, total surface heat flux, and turbulent kinetic energy input. Surface mixed layer salinity is relaxed towards the Levitus annual mean salinity fields, while the salinity in the interior isopycnal layers is dynamically determined without such a constraint. Instantaneous atmospheric fields are interpolated from the monthly means. Monthly mean climatology of chlorophyll pigment concentrations were obtained from the Coastal Zone Color Scanner (CZCS) from November 1978 to June 1986 (Feldman et al 1989). The control run with clearwater parameterization (A) of OPYC was carried out for 50 years, which is sufficient to obtain a cyclo-stationary state for the upper ocean, i.e., the thermocline. Because no interannual variability can develop when Newtonian feedbacks towards climatological data are present, it was sufficient to take the restart conditions from the last year of this 50-year control-integration (A). The numerical model experiments with chlorophyll pigment parameterization (B) were conducted for additional 10 years, until another cyclo-stationary state for global ocean SST was obtained. 

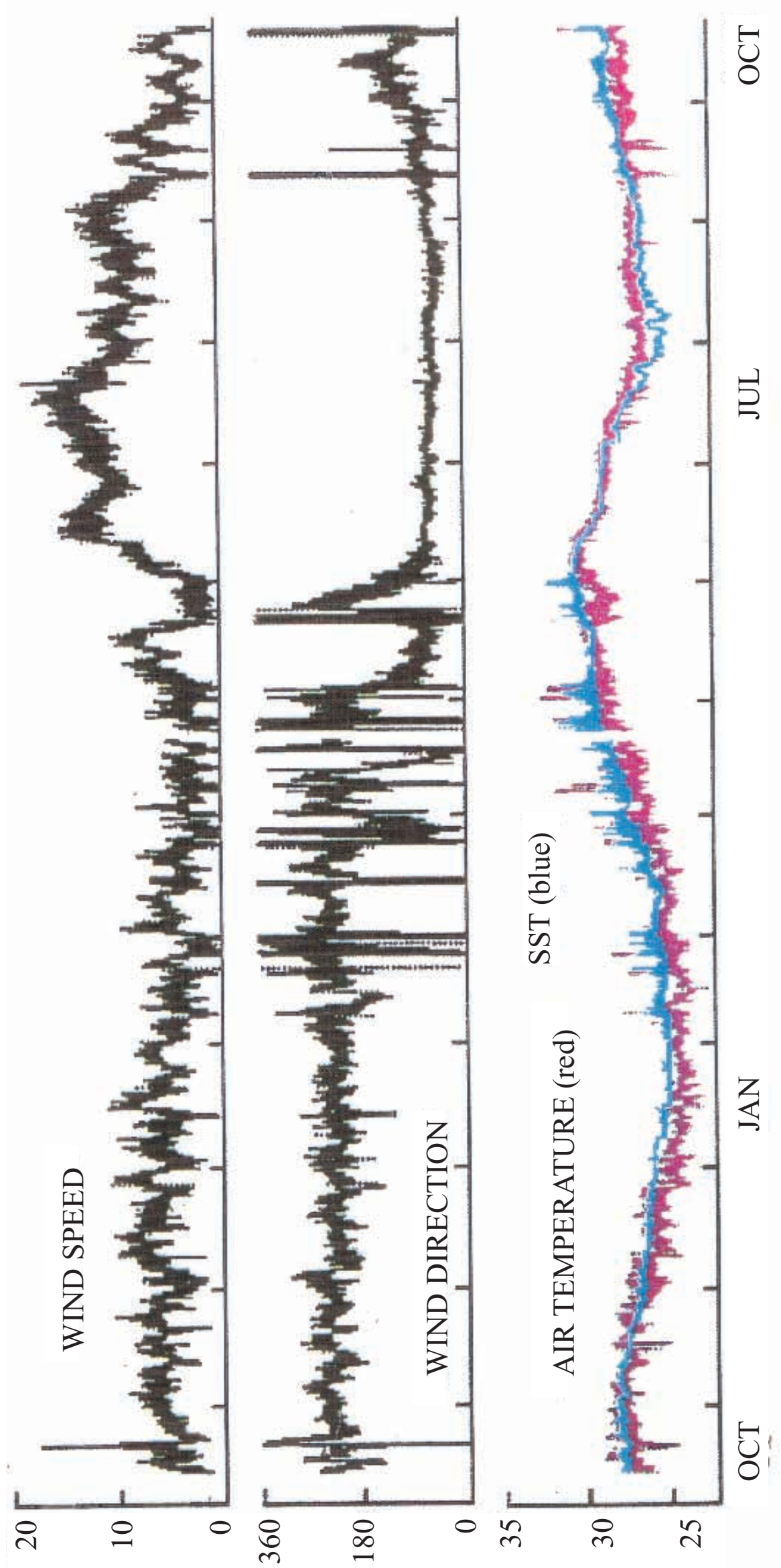

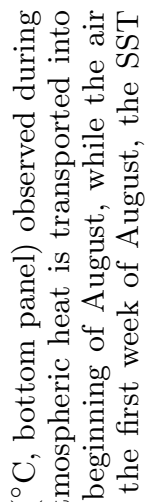

要运

$\sqsupseteq$

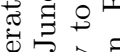

实.寻要

记

교 용

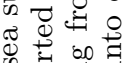

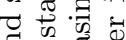

ฮี

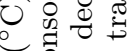

䂧

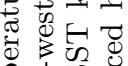

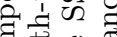

『

สี

बิ

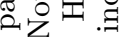

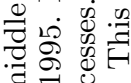

ه

要

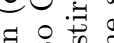

获

$\exists \rightarrow$

동

उ.

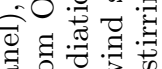

$\approx$

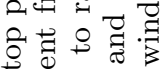

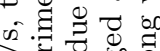

द्व

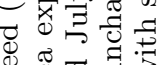

\&.

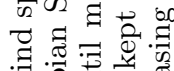

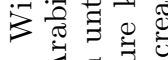

- 公范范

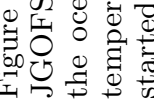



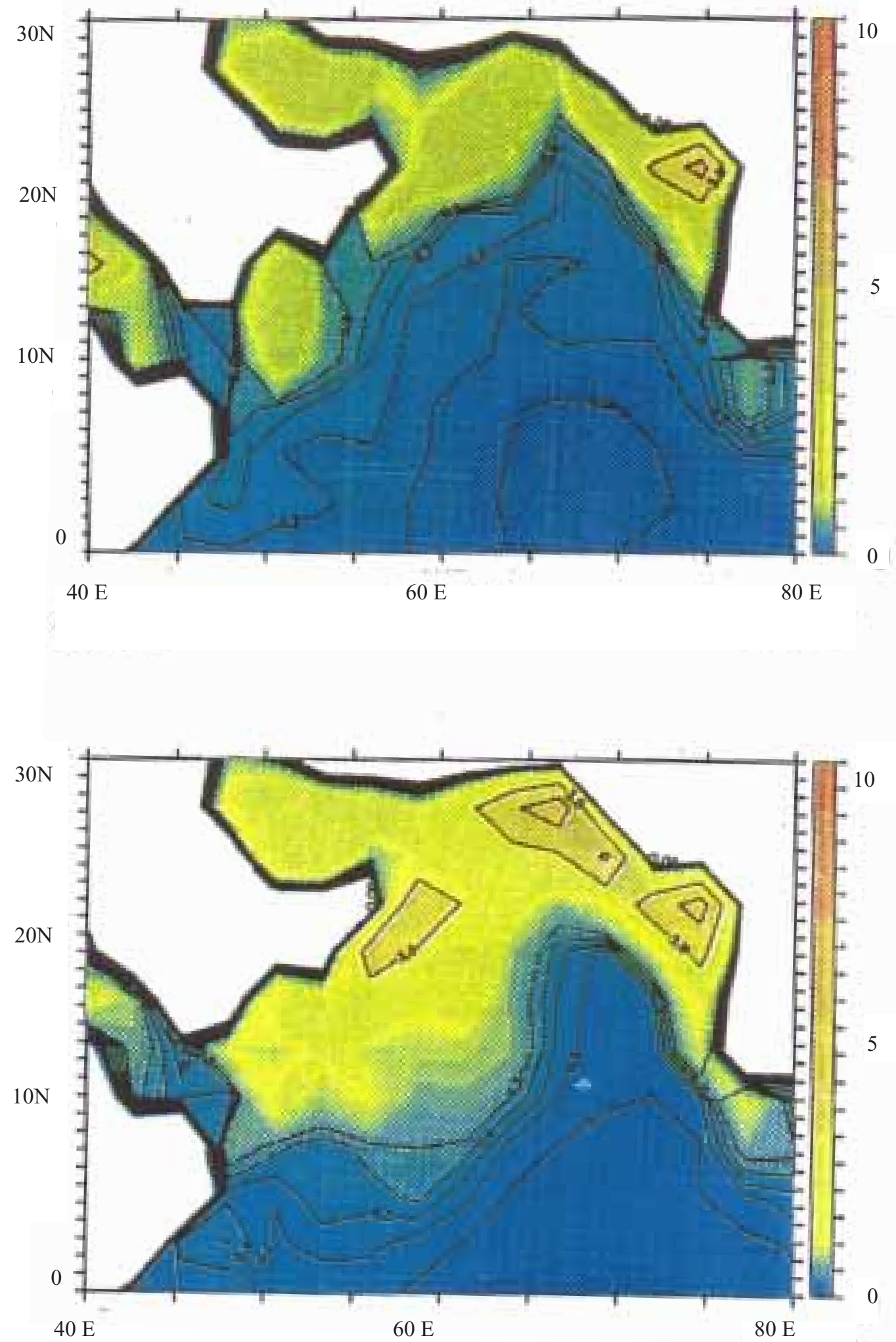

Figure 2. Monthly averaged value of CZCS satellite observed chlorophyll pigment concentration ( $\left.\mathrm{mg} / \mathrm{m}^{3}\right)$ in July (top panel) and in October (bottom panel).

\section{Arabian Sea surface temperature}

Model results of upper ocean biological heating on a zonal strip along $20^{\circ} \mathrm{N}$ in the Arabian Sea are discussed with JGOFS in situ observations during summer monsoon (Dickey et al 1998) for this region. In the JGOFS observations, southwest monsoon started to blow from the beginning 

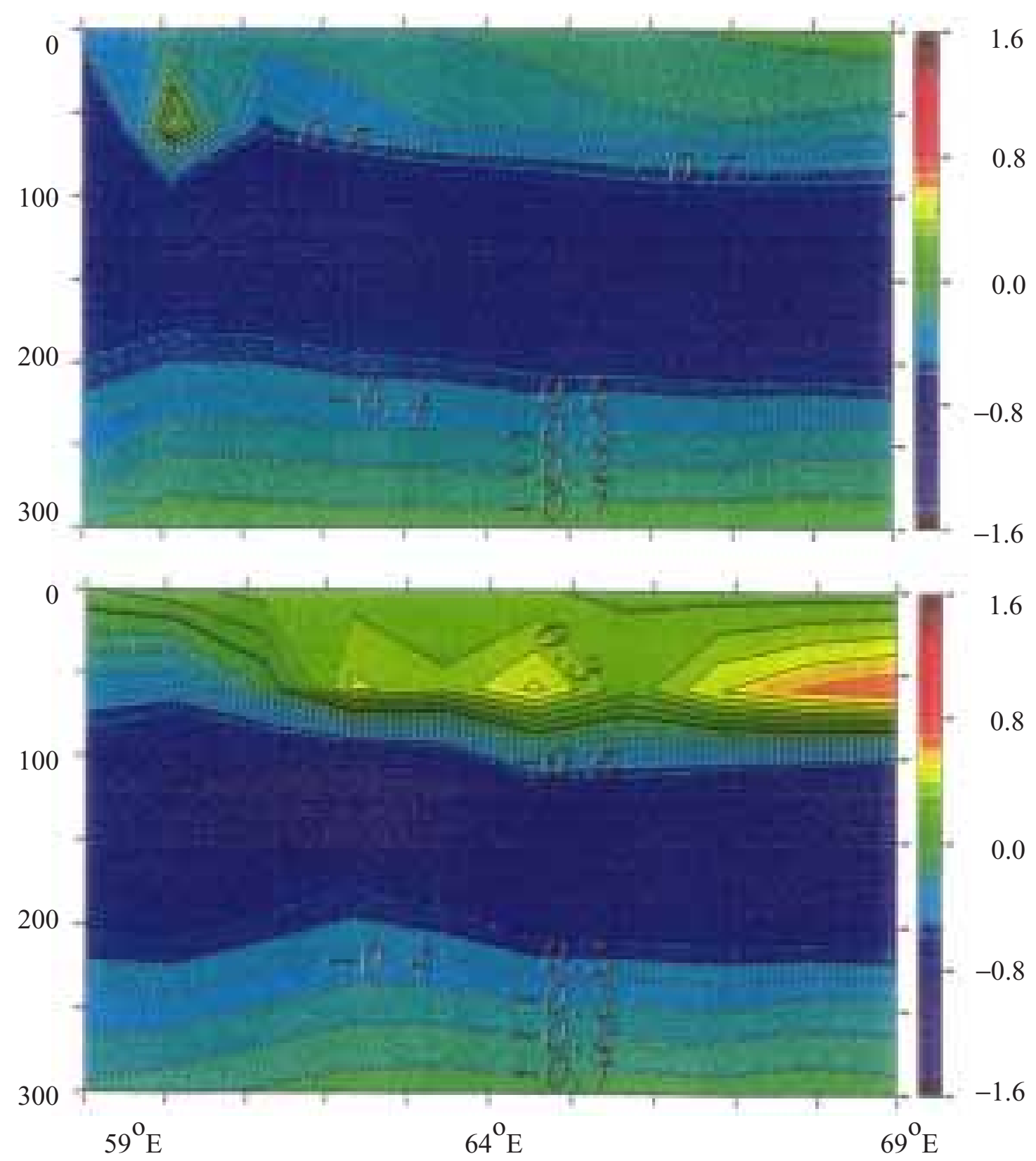

Figure 3. Vertical section of anomalous temperature $\left({ }^{\circ} \mathrm{C}\right.$ ) along $20^{\circ} \mathrm{N}$ for July (upper panel) and October (bottom panel).

of June to mid September (figure 1). The mixed layer base (estimated from their observations as the depth of isotherm that is $1^{\circ} \mathrm{K}$ less than the sea surface temperature) started deepening until mid July with increasing monsoon wind, however, the mixed layer bottom started shoaling afterwards (Figure 5 in Dickey et al 1998). We can interpret the mixed layer thickness increase due to the input of turbulent kinetic energy from south-west monsoon from the beginning of June to mid July: in their observations the waters from sea surface to $80 \mathrm{~m}$ are completely mixed so that the temperature from sea surface to $80 \mathrm{~m}$ depth become nearly homogeneous when strong wind stirring is executed in July (figure 5 of Dickey et al 1998). In JGOFS obser- vations, chlorophyll concentration decreases during this period due to increased entrained water from layer below. It is noted that the entrained water is nutrient rich and cold, however, the chlorophyll concentration in the entrained water is not significant (figure 5 of Dickey et al. 1998). Figure 2 displays satellite derived CZCS chlorophyll concentration in July and in October. JGOFS observations showed mixed layer started stratification from mid July: the waters of upper ocean from surface to $35 \mathrm{~m}$ gradually become warm, while the waters below started cooling even when the monsoon wind is stronger than before (figure 5 in Dickey et al. 1998). Dickey et al's figure 5 shows such synchronization between upper water warming and lower 

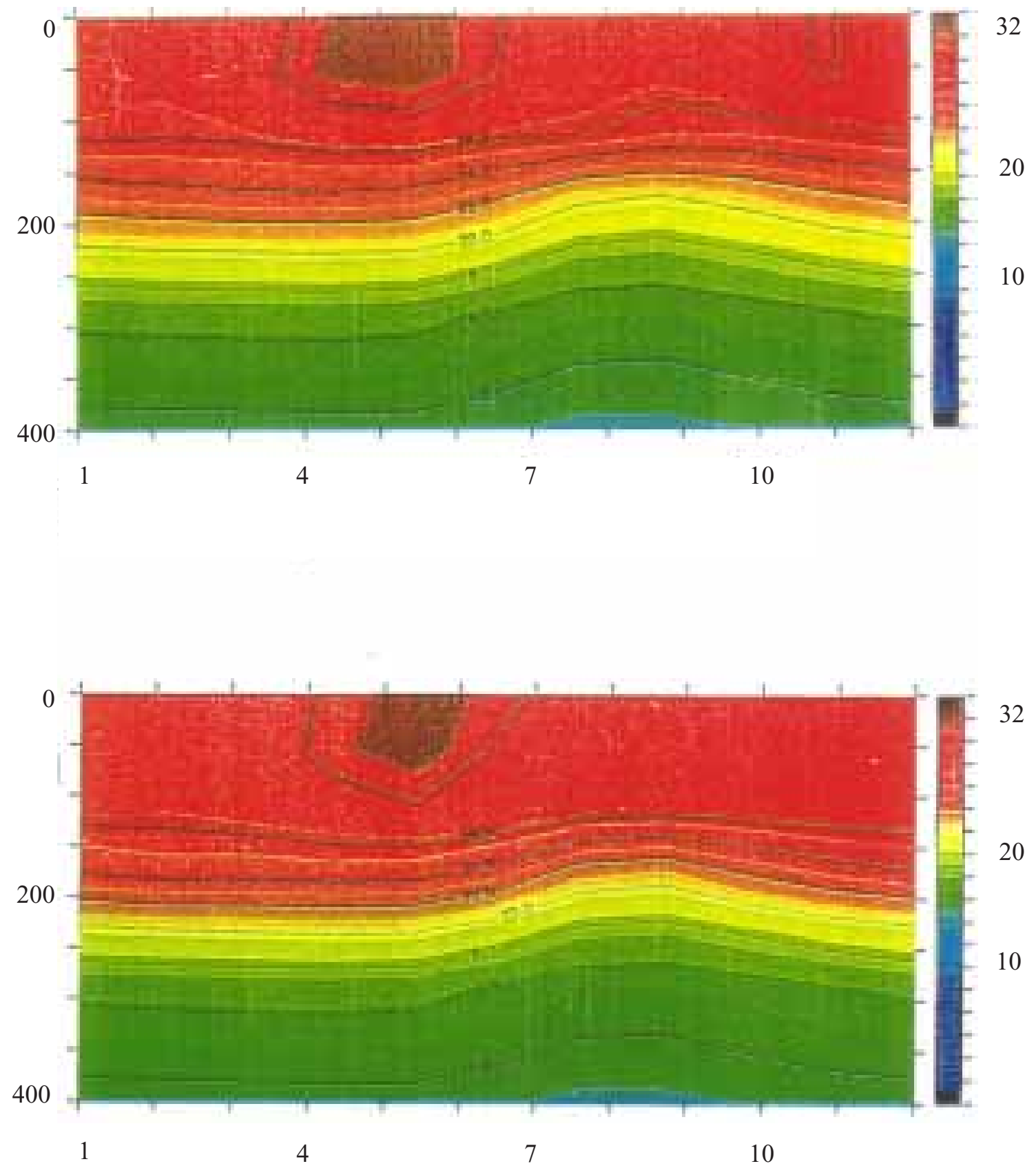

Figure 4. Time-depth plots of temperature $\left({ }^{\circ} \mathrm{C}\right)$ from numerical simulations with (upper panel) and without (bottom panel) chlorophyll pigments. The upper panel shows SST increase above $28^{\circ} \mathrm{C}$ in late October and significant subsurface temperature decrease compared with simulation without chlorophyll (bottom panel).

water cooling from late July to late August during the south-west monsoon: the upper portion of the water column represented by the top three temperature moorings at depths of $1.8 \mathrm{~m}, 10 \mathrm{~m}$, and $35 \mathrm{~m}$ is warming and the lower moorings located at depths of $65 \mathrm{~m}$ and $80 \mathrm{~m}$ is cooling in a synchronized manner.

It is important to note that south-west monsoon is at its strongest at this time when the upper layer is warming and the lower layer is cooling. Incoming solar radiation started increasing from its lowest at July. In JGOFS observations, the vertical distribution of chlorophyll concentration does not support any water mass migration near the depths around $35 \mathrm{~m}$ and $65 \mathrm{~m}$ : the vertical chlorophyll distribution shows homogeneity in its concentration, which excludes the existence of two different water masses. Figure 3 displays the vertical section of anomalous temperature, which is the difference between the temperature from the chlorophyll run (A) and that of clear water run (B) along $20 \mathrm{~N}$ in July (upper panel) and in October (lower panel). Because of the increase of chlorophyll concentration from July to October, surface warming and 
subsurface cooling becomes significant from July to October.

The figure 4 is the vertical sections of simulated water temperatures with and without the effect of chlorophyll heating mechanism. It is seen that the water temperature increases between surface to $50 \mathrm{~m}$ and it decreases below $50 \mathrm{~m}$ in the presence of chlorophyll pigments than without chlorophyll pigments. A similar surface warming and subsurface cooling was observed with increased chlorophyll pigment concentration, biological heating rate, and decreased mixed layer thickness during the southwest monsoon period (August-September) (Dickey et al 1998). As depicted in the bulk mixed layer theory, oceanic mixed layer thickness decreases due to the biological heating (not shown), whereas sublayer temperature decreases due to reduced penetration of solar radiation (figure 3 ). It is the effect of phytoplankton on solar radiation transfer in the vertical one dimension.

\section{Anomalous subsurface currents in the equatorial Pacific}

Overall assessment of the global scale influence of chlorophyll distribution with horizontal advection effect must be needed in realistic application in three dimensional ocean modeling. Applying the previous one dimensional argument in the equatorial ocean, we may state that the mixed layer bottom must rise where chlorophyll shifts the solar radiation towards surface, as shown in our numerical experiment (figure 5). It is noted that even modest concentration of chlorophyll pigments less than $0.3 \mathrm{mg} / \mathrm{m}^{3}$ is enough to lift the mixed layer base up to $20 \mathrm{~m}$ in the equatorial Pacific.

The meridional differential heating and associated meridional gradient of the mixed layer base can lead to geostrophically adjusted westward current with the length scale of equatorial wave-guide dynamics of $500 \mathrm{~km}$ in both hemispheres in the tropical Pacific (figure 3 of Nakamoto et al 2001). In our numerical model experiments, the maximum value of the geostrophically generated currents in the 4 th layer is $3 \mathrm{~cm} / \mathrm{sec}$. These westward anomalous currents in the 4th layer in the model arrive at the western boundary in the tropical Pacific to join the equatorial undercurrent (EUC), thus strengthening the EUC (figure 6).

During La Nina of 1988 (Kirk 1988), the EPOC observation was conducted in the eastern equatorial Pacific (Chaves et al 1990). It is interesting to note that the isotherm and isopleths of the central and eastern Pacific were raised (figure 4 of Chaves et al 1990). They interpreted high chlorophyll concentration as a secondary effect of upwelling strengthened during the La Nina period. However, this does not completely explain the fact that the subsurface layer between $14^{\circ} \mathrm{C}$ isotherm and $13^{\circ} \mathrm{C}$ isotherm thickened, and the layer of nitrate concentration of 20-24 micro-mol thickened (figure 4 in Chavez et al 1990). (Note that the conventional interpretation of wind driven equatorial upwelling does accompany no sub-surface layer thickening).

In the eastern equatorial Pacific, the anomalous water masses transported by strengthened EUC must up-well towards the surface, while subsurface layer thickness increases (figure 4 of Nakamoto et al 2001). This upwelling induced by chlorophyll pigments is accompanied by mixed layer lifting with subsurface-layer thickening. Note that the equatorial upwelling induced by trade wind is not accompanied by such subsurface layer thickening.

\section{Discussion}

Our numerical model experiment suggested that, when chlorophyll pigment concentration peaks in October, the upper ocean warms and the subsurface cools through the effect of vertical distribution of absorbed solar energy, with more energy absorbed in the surface layers and less energy penetrating towards the lower layers than the case without chlorophyll pigments. This is confirmed from the U.S. JGOFS moored buoy measurements near the Arabian coast $\left(15.5^{\circ} \mathrm{N}, 61.5^{\circ} \mathrm{E}\right)$.

From the Arabian JGOFS mooring data, we speculate that the chlorophyll concentration started blooming due to entraining of nutrient-rich cold water due to wind stirring. In the first week of July, chlorophyll concentration became $0.4 \mathrm{mg} / \mathrm{m}^{3}$ at the depth about $50 \mathrm{~m}$. At that time, the incoming solar radiation is trapped due to phytoplankton at upper layers (from surface to $35 \mathrm{~m}$ ), while the lower layers (from $65 \mathrm{~m}$ to $80 \mathrm{~m}$ ) does not receive the same solar energy as before the chlorophyll blooming in the previous month.

In the equatorial Pacific where horizontal advection effect is important, the effect of chlorophyll pigment on vertical penetration of solar radiation interact with the equatorial ocean circulation dynamics. We propose that the observed increase of nitrate concentration and subsurface layer thickness between $140 \mathrm{~W}$ and $110 \mathrm{~W}$ during EPOC experiment as shown in Chavez and Barber (1987) can also be explained as the strengthened horizontal transport of nitrate by the strengthened equatorial undercurrent (EUC) as in Nakamoto et al (2001). Figure 5 of Chavez and Barber (1987) displays asymmetric distribution of nutrients across the equator at $110 \mathrm{~W}$, indicating strong upwelling shifted towards the north of the equator (Chavez and Barber 1987). Figure 7 is the comparison of 


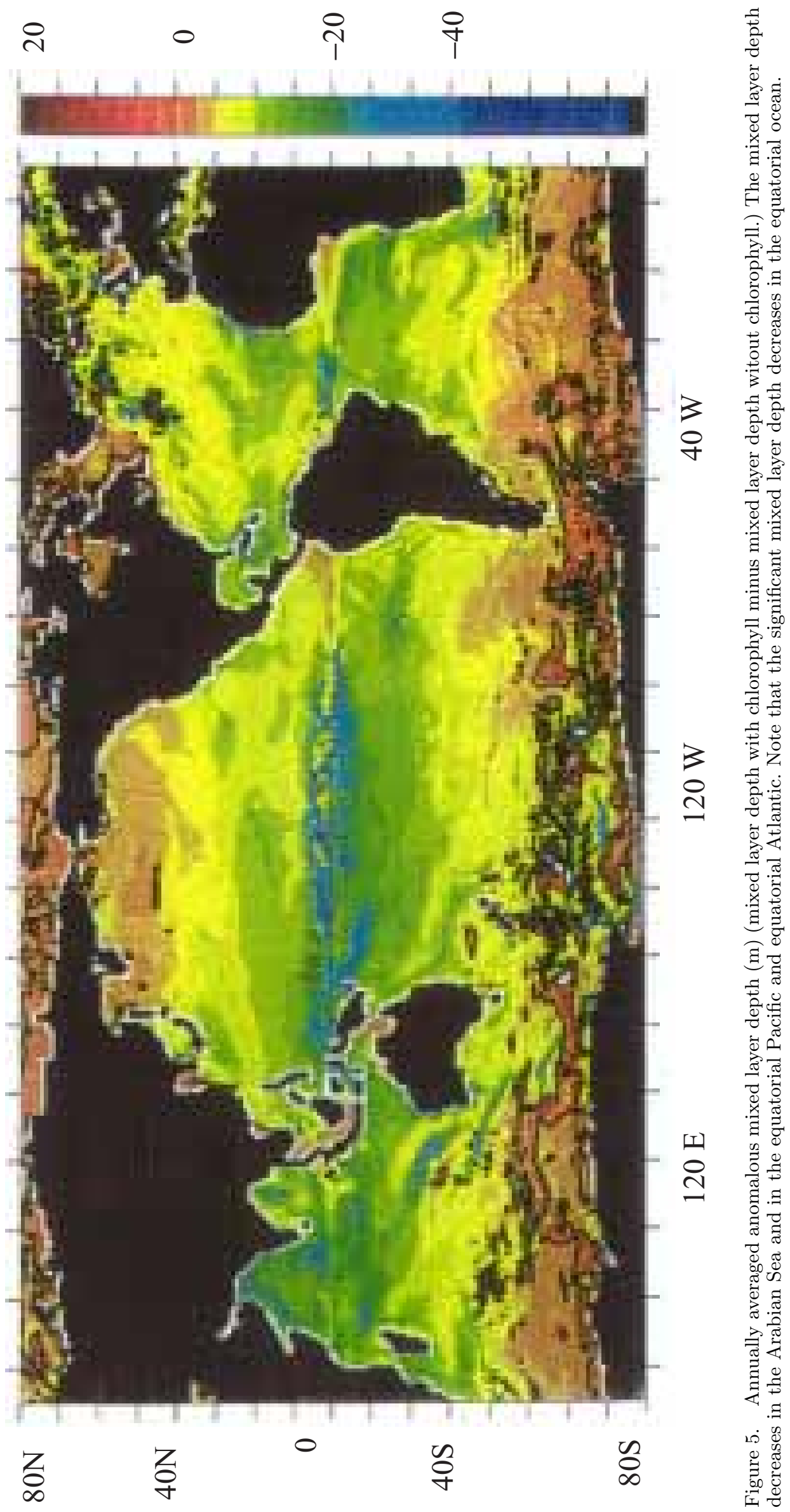




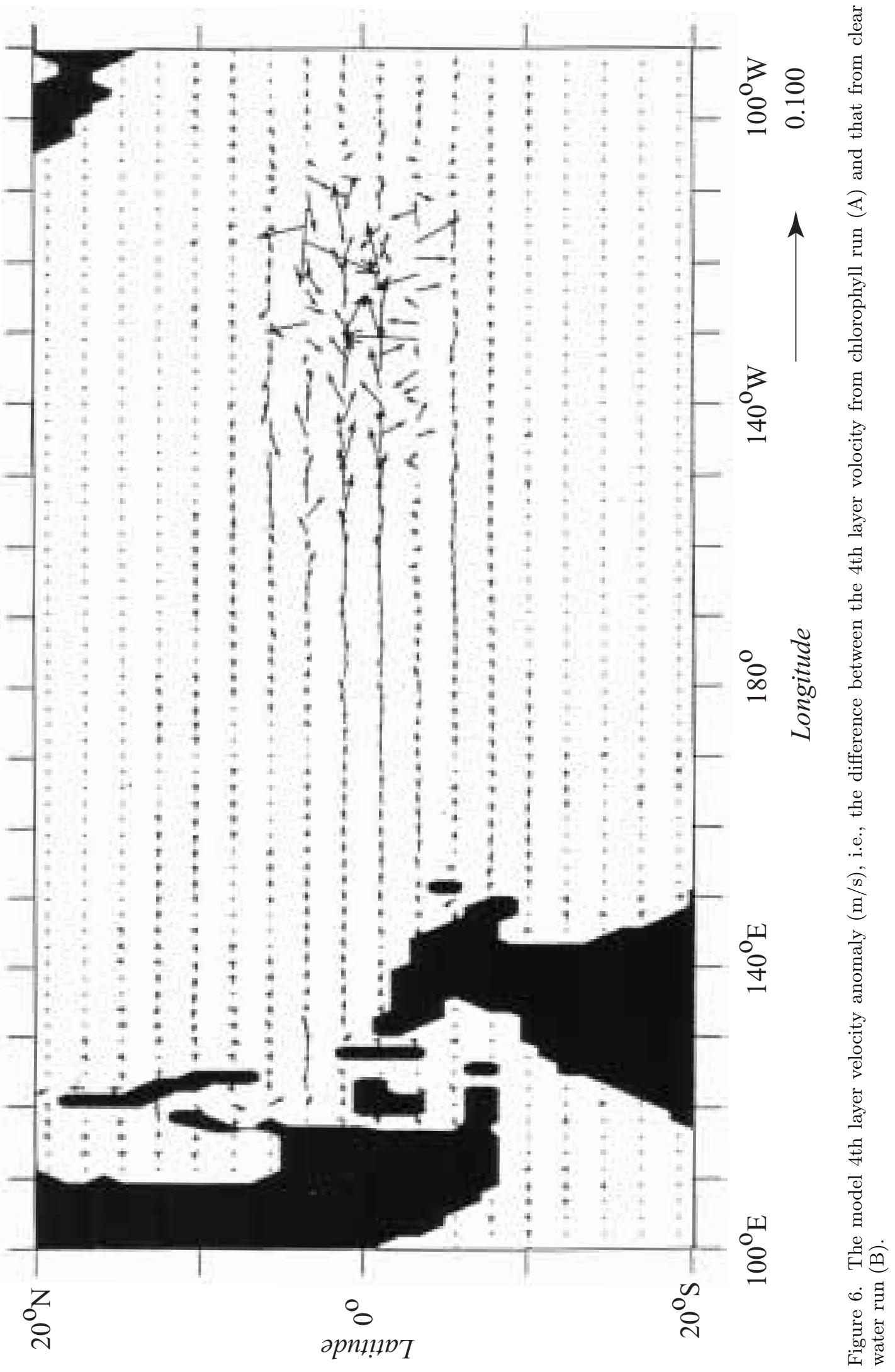



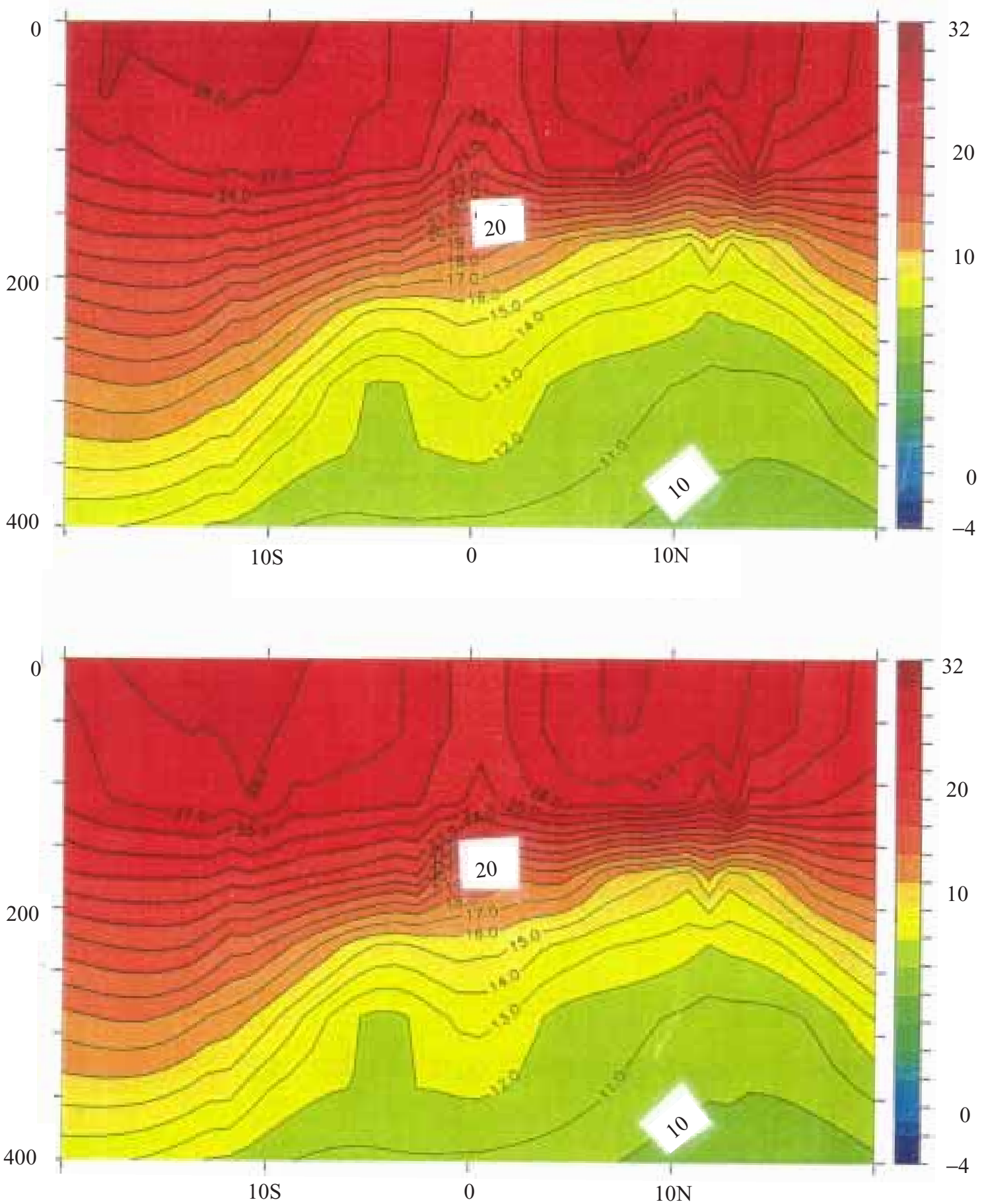

Figure 7. Vertical section of temperature $\left({ }^{\circ} \mathrm{C}\right.$ ) along $140^{\circ} \mathrm{W}$ from $20^{\circ} \mathrm{S}$ to $20^{\circ} \mathrm{N}$ with (upper panel) and without (bottom panel). It is noted that the $25^{\circ} \mathrm{C}$ isotherm at the equator is located around the depth of $70 \mathrm{~m}$ and the equatorial under current (EUC) is strengthened when chlorophyll accumulate solar radiation.

vertical section of temperatures at $140 \mathrm{~W}$ with and without chlorophyll pigments. The $25^{\circ} \mathrm{C}$ isotherm with chlorophyll pigment is located shallower and asymmetric across the equator than that without chlorophyll pigments.

Based on these similarities between the JGOFS observations and our numerical modeling with chlorophyll pigment introduced in the bulk mixed layer formalism, we feel that the observed thickening of subsurface layers defined by temperature and nitrate concentration may be caused by phytoplankton's heating effect in the eastern equatorial Pacific during the La Nina period in 1988.

It is noted that the use of OPYC's standard heat flux parameterization implicitly contains some Newtonian feedback for the SST, thus modeled 
SST anomalies might be more pronounced if a coupled ocean-atmosphere model with more realistic feedbacks would be used.

\section{Summary}

Observed spatial and temporal anomalies derived from the JGOFS Arabian Sea process study and EPOCS bio-physical observations during the La Nina period of 1988 are in agreement with results obtained from the model simulation. The spatial and temporal variation of both SST and chlorophyll pigments leads to regional-scale variations in the atmosphere on similar scales.

The sub-layer thickening and cooling associated with the mixed-layer thinning and warming increases vertical stratification in the upper thermocline, and redistributes nutrients, besides heat and salt. Thus, it is suggested that the biological influence of ocean mixed layer thermodynamics may modulate upper ocean circulation in global basin scale.

In this paper, we emphasized that the biological effect on ocean circulation should be studied with three dimensional approach including vertical radiation transfer process and horizontal advection of the rotating earth dynamics. One such approach is to use satellite and in situ dada combined with a Mixed layer isopycnal Ocean General Circulation Model (OPYC) that includes physics and thermodynamics representing the effect of biology on buoyancy in the upper ocean mixed layer.

\section{Acknowledgements}

The model optimization and chlorophyll pigment scheme coding started on a SX4 supercomputer of Japan Marine Science and Technology Center in 1996. Kazuhiro Ban, Kazusi Furuta, and Kuniko Numata helped with running the model and processing much of the model data. This research was conducted when S P K visited Earth Science and Technology Organization (ESTO) and Japan Marine Science and Technology Center (JAMSTEC) in February and October in 1999. R F received support from the National Aeronautics and Space Administration under grant NAG5-6202. This is a contribution to "Study of global carbon cycle and related carbon flux mapping using satellite images" under the Japanese Science and Technology Agency, and is also a contribution of National Institute of Oceanography of India (No. 3772).

\section{References}

Chavez P F and R T Barber 1987 An estimate of new production in the equatorial Pacific; Deep Sea Res. 34 129-1243

Chavez F P, Buck K, Barber R T 1990 Phytoplankton taxa in relation to production in the equatorial Pacific; Deep Sea Res. 37 1733-1752

Dickey T, Marra J, Sigurdon D E, Weller R A, Kinkade C S, Zedler S E, Wiggert J D and Langdon C 1998 Seasonal variability of bio-optical and physical properties in the Arabian Sea: October 1994-October 1995; Deep Sea Res., II, 45 2001-2025

Feldman G C 1989 Ocean Color: Availability of the Global Data Set; EOS Trans. 70634

Ivanoff A 1977 Oceanic absorption of solar energy, In: Modelling and Prediction of the Upper Layers of the Ocean, E B Kraus, (New York: Pergamon) 326pp.

Kirk J T O 1988 Solar heating of water bodies as influenced by their inherent optical properties; J. Geophys. Res. 93 10897

Lewis M A, Carr M E, Feldman G C, Esaias W and McClain C 1990 Influence of penetrating solar radiation on the heat budget of the equatorial Pacific Ocean; Nature 347 543-545

Martin P J 1985 Simulation of the mixed layer at OWS November and Papa with several models; J. Geophys. Res. 90 903-916

Morel A and Antoine D 1994 Heating rate within the upper ocean in relation to its bio-optical state; J. Phys. Oceanogr 24 1652-1665

Nakamoto S, Prasanna-Kumar S, Oberhuber J M, Muneyama K, Frouin R 2000 Chlorophyll modulation of sea surface temperature in the Arabian Sea in a mixed layer-isopycnal general circulation model; Geophys. Res. Lett. 27, 747-750

Nakamoto S, Prasanna-Kumar S, Oberhuber J M, Ishizaka J, Muneyama K, Frouin R 2001 Response of the equatorial Pacific to chlorophyll pigment in a mixed layerisopycnal ocean general circulation model; Geophys. Res. Lett. 28, 2021-2024

Oberhuber J M 1993 Simulation of the Atlantic circulation with a coupled sea ice-Mixed Layer-Isopycnal general circulation model. Part I: model description; J. Phys. Oceanogr. 23 808-829

Paulson C A and Simpson J J 1977 Irradiance measurements in the upper ocean; J. Phys. Oceanogr. 7 952-956

Simonot J Y, Dollinger E and Le Treut H 1988 Thermodynamic-Biological-Optical-Coupling in the oceanic mixed layer; J. Geophys. Res. 93 8193-8202

Sathyendranath S, Gouveia A D, Shetye S R and Platt T 1991 Biological controls of surface temperature in the Arabian Sea, Nature 349, 54-56 